\title{
A INVISIBILIDADE DA IMIGRAÇÃO GALEGA E A PRODUÇÃO DE UMA IDENTIDADE SOCIAL HIBRIDA NAS NOVAS TERRAS (SÃO PAULO, 1880-1910)
}

La invisibilidad de la inmigración de gallega y la producción de una
identidad social híbrida en las nuevas tierras (São Paulo, 1880-1910)

\begin{abstract}
The invisibility of Galician immigration and the production of a hybrid social identity in the new lands (São Paulo, 1880-1910)
\end{abstract}

\section{Maurilane de Souza Biccas ${ }^{\alpha}$ e Diana Gonçalves Vidal ${ }^{\beta}$}

Data de recepção: 07/11/2019 • Data de aceitação: 18/12/2019

Resumo. O artigo explora as características da emigração galega ao Brasil entre o final do século XIX e início do XX, concentrando-se na região de São Paulo. Está organizado em duas partes complementares. Na primeira, debruça-se sobre a historiografia acerca da temática, inquirindo estatísticas e procurando perscrutar o perfil do migrante galego que busca a travessia oceânica. No mesmo apartado, discorre sobre o que consideramos a dupla invisibilidade da imigração galega, confundida com a portuguesa do Norte de Portugal ou com a generalidade da imigração espanhola nos registros oficiais de entrada no país. No segundo apartado, o Centro Español de Santos e a escola por ele constituída são objeto de análise de modo a perceber como os imigrantes galegos foram produzindo uma identidade social hibrida a partir de uma prática associativista. Nos Comentários finais, tecem-se algumas indagações acerca da denominação da entidade.

Palavras-chave: Migração; Centro Español; associativismo; educação escolar; história da educação.

\footnotetext{
a Departamento de Filosofía e Ciências da Educação, Faculdade de Educação, USP. Rua Paraguassu 476 ap 12. Perdizes, São Paulo, SP, CEP 05006-011, Brasil. msbiccas@usp.br. (D) https://orcid. org/0000-0002-5246-4742

${ }^{\text {B }}$ Departamento de Filosofía e Ciências da Educação, Faculdade de Educação, e Instituto de Estudos Brasileiros, USP. Brasil. dvidal@usp.br (1) https://orcid.org/0000-0002-7592-0448
} 
Resumen. El artículo explora las características de la emigración gallega a Brasil entre finales del siglo XIX y principios del XX, centrándose en la región de São Paulo. Está organizado en dospartes complementarias. En la primera, se ocupa de la historiografía sobre el tema, indagando estadísticas e intentando examinar el perfil del migrante gallego que busca cruzar el océano. En la misma sección, analiza lo que consideramos la doble invisibilidad de la inmigración gallega, mezclada con los portugueses del norte de Portugal o con la generalidad de la inmigración española en los registros oficiales de entrada al país. En la segunda sección, el Centro Español de Santos y la escuela creada por él son objeto de análisis para comprender cómo los inmigrantes gallegos produjeron una identidad social híbrida a partir de una práctica asociativa. En los Comentarios finales, se hacen algunas preguntas sobre la denominación de la entidad.

Palabras clave: Migración; Centro Español; sociabilidad; educación escolar; historia de la educación.

Abstract. The article explores the characteristics of Galician emigration to Brazil between the late 19th and early 20th centuries, focusing on the São Paulo region. It is organized into two complementary parts. In the first one, it deals with the historiography on the subject, inquiring statistics and trying to examine the profile of the Galician migrant who seeks the ocean crossing. In the same section, it discusses what we consider the double invisibility of Galician immigration, mixed with the Portuguese from the northern Portugal or with the generality of Spanish immigration in the official records of entry into the country. In the second section, the Centro Español de Santos and the school created by it are the subject of analysis in order to understand how the Galician immigrants produced a hybrid social identity from an associative practice. In the Final Comments, some questions are asked about the denomination of the entity.

Keywords: Migration; Centro Español; associativism; schooling; history of education.

\section{INTRODUÇÃO}

Drauzio Varella, no livro Nas Ruas do Brás, inicia o texto com algumas memórias da sua infância, da família e do bairro em que viveu na cidade de São Paulo. A primeira história é sobre o avô paterno, um galeguinho de 12 anos que resolveu que queria fazer a América, no final do século XIX.

Numa noite de neve na aldeia, depois que os irmãos menores dormiram, meu avô sentou ao lado da mãe, na luz quente do fogão a lenha: 
- Mãe, eu quero ir ao Brasil, quero ser um homem de respeito, trabalhar e mandar dinheiro para a senhora criar os meus irmãos.

Ela fez o que pode para convencê-lo a ficar. Pediu que esperasse um pouco mais, era ainda um menino, mas ele estava determinado:

- Não vou pastorear ovelhas até morrer, como fez o pai.

Mais tarde, como em outras noites de frio, a mãe foi por uma garrafa de água quente entre as cobertas para esquentar a cama dele:

- Doze anos, meu filho, quase um homem. Você tem razão, a Espanha pouco pode nos dar. Vá para o Brasil, terra nova cheia de oportunidades. E trabalhe duro, siga o exemplo do seu pai.

Meu avô viu os olhos de sua mãe brilharem como líquido. Desde a morte do marido, era a primeira vez que chorava na frente de um filho. ${ }^{1}$

Fazer a América tem um sentido muito particular, abordado na história de Varella, significa ir para um país americano e ganhar dinheiro para o sustento dos familiares e de si mesmo. Este é um, entre os milhões de casos de emigração ocorridos na Galícia nesse período, quando a população pobre vislumbrou uma possibilidade de construir uma vida melhor alhures.

No relato, Varella ainda anuncia que seu avô era «analfabeto, desembarcou em Santos com uma calça, uma camisa, um par de meias e o capote na malinha».2 Quando chegou em São Paulo foi morar no Brás, bairro industrial próximo da região central da cidade, e comprou uma carroça para entregar mercadorias. "Como não sabia ler e precisava assinar recibos, pagou um garrafão de vinho para que um espanhol mais velho lhe ensinasse». ${ }^{3}$

\footnotetext{
1 Drauzio Varella, Nas Ruas do Brás (São Paulo: Cia das Letras, 2000), 3-4.

2 Varella, Nas Ruas do Brás, 4.

3 Varella, Nas Ruas do Brás, 4.
} 
O fragmento que abre este artigo traz elementos importantes que ajudam a compreender algumas das causas e condições em que muitos galegos vieram para o Brasil. Para desdobrá-los, decidimos estruturar o texto em duas partes. Na primeira, realizamos uma discussão sobre a invisibilidade da imigração galega no Brasil e sobre o silêncio das fontes e destacamos a presença espanhola e galega no Estado de São Paulo. Na segunda, enfatizamos a organização e o funcionamento do Centro Español, criado na cidade de Santos, em 6 de janeiro de 1895, e a produção das memórias dessa instituição como meio de constituir uma nova identidade social, entre o final do século XIX e a primeira década do século XX.

As fontes utilizadas foram coletadas na Biblioteca Geral e na Hemeroteca da Universidade de Santiago de Compostela, tais como: periódicos galegos e argentinos; anais de congressos realizados na Espanha; memórias de associações galegas criadas na América do Sul; estatutos e atas do Centro Español; livros produzidos na Espanha, Argentina e Cuba e que circularam no Brasil, no final do século XIX e início do século XX.

\section{INVISIBILIDADE GALEGA NO BRASIL: O SILÊNCIO DAS FONTES}

Nas últimas décadas foram elaborados vários estudos sobre a emigração galega para a América. ${ }^{4}$ As primeiras investigações historiográficas

\footnotetext{
${ }^{4}$ Antón Costa Rico, «As sociedades dos "Americanos" e a educación en Galicia», Revista da Comisión Galega do Quinto Centenário 5 (1990): 89-140. Antón Costa Rico, «Emigrantes, escuelas y regeneración social: los emigrantes gallegos a América y el impulso a la educación (1879-1936)», Revista Brasileira de História da Educação 16 (2008): 13-45. Narciso de Gabriel, «Emigración y alfabetización en Galicia», Historia de la educación. Revista interuniversitaria 4 (1985): 321-336. Mais recentemente do mesmo autor onde, entre outros factores, se relaciona o fenómeno da emigración galega com o da alfabetización: «El proceso de alfabetización en Galicia: un intento de explicación y de comprensión», Historia de la educación. Revista interuniversitaria 32 (2013): 289-313. Herbert S. Klein, A imigração espanhola no Brasil (São Paulo: Editora Sumaré /FAPESP, 1994). Xosé M. Malheiro Gutiérrez, «Mobilización societaria, correntes de pensamento e escolas de emigrantes en Galicia durante o primeiro tercio do século XX: o protagonismo de Ignacio Ares de Parga e Antón Alonso Ríos» (Tesis doctoral, Universidad de Santiago de Compostela, 2003). Vicente Peña Saavedra, «Presupuestos socioeducativos para la implantación de las escuelas de americanos y las Sociedades de Instrucción en Galicia», Historia de la educación. Revista interuniversitaria 2 (1983): 359-369. Vicente Peña Saavedra, «As escolas que viñeron de alén mar (Galicia, ss. XVII-XXI). Algunhas réplicas dende terras lusas», Revista da Faculdade de Letras. História. III Série 3 (2002): 245-262. Elena Pájaro Peres, A inexistência da Terra Firme: A imigração Galega em São Paulo, 1946-1964 (São Paulo: Edusp, 2003). Elaine Veiga Porta, Os imigrantes Espanhóis em Santos (1880-1920) (Doutorado: Faculdade de Ciencias e Letras da Universidade de São Paulo, 2008). Érica Sarmiento da Silva, O outro rio. A emigração galega a Rio de Janeiro (Santa Comba, A Coruña: TresCtres, 2006). Diana Gonçalves Vidal, «Galicia e Brasil: tecendo histórias da educação (1871-1936)», Sarmiento. Anuario Galego de Historia da Educación 12 (2008): 111-126. Marília Dalva Klaumann Cánovas, A emigração espanhola e a trajetória do imigrante na cafeicultura paulista: o caso de
} 
realizadas trazem a marca quantitativa na sua abordagem, destacando os aspectos demográficos e econômicos, percebidos a partir das consequências da emigração e da movimentação de recursos financeiros. Outros estudos focaram a relação dessas iniciativas com o desenvolvimento educativo na Galicia e nos países da América que receberam os galegos entre o final do século XIX e o início do XX, evidenciando a disseminação de práticas de associativismo. Em particular, estes estudos historiográficos, efetuados tanto na Espanha quanto no Brasil, têm procurado compreender a relação entre migração e instrução, a partir da instalação de Sociedades de Beneficência e de Instrução nos dois lados do Atlântico.

Combinando as duas vertentes, dispomo-nos neste apartado a esboçar dados estatísticos sobre a migração galega para o Brasil e, em particular, para São Paulo, de modo a dimensionar a magnitude desse fluxo de pessoas. No apartado seguinte, reposicionamos a lente de observação e analisamos o caso do Centro Español de Santos, com o propósito de anunciar algumas das práticas educativas implantadas pela associação. ${ }^{5}$

Segundo os dados estatísticos oficiais, ao final do século XIX e nas primeiras décadas do século XX, 50.000.000 de europeus deixaram seus países de origem em direção ao outro lado do Atlântico. Este certamente foi um dos mais importantes acontecimentos sociais da Europa à época. Vicente Peña Saavedra chama a atenção para o fato de $84 \%$ dos emigrantes terem saído de cinco áreas territoriais: Ilhas Britânicas, Itália, Áustria-Hungria, Alemanha e Espanha. Destaca também que aproximadamente $86 \%$ dessas saídas foram em direção a América e, desse contingente, entre 1882 a 1930, segundo registros oficiais deixaram a Espanha 3.297 .312 indivíduos. $^{6}$

Villa Novaes, 1880-1930 (Mestrado: FFLCH-USP, 2001). Marília Dalva Klaumann Cánovas, «Imigrantes espanhóis na cafeicultura paulista, 1880-1930: protagonistas ou coadjuvantes», Revista História Hoje. Revista eletrônica de história 2, no. 6 (2005): 1-16.

${ }_{5}^{5}$ Para um maior detalhamento sobre a relação entre o Centro Español e a educação, conferir a dissertação de mestrado de Karime Antigo, ainda em andamento, sob a orientação de Diana Gonçalves Vidal, na Faculdade de Educação da USP.

${ }^{6}$ Vicente Peña Saavedra, «Los emigrantes transoceânicos como agentes de modernización educativa em el norte penunsular», en La educación en España a examen (1898-1998), coords. Julio Ruíz Berrio et al. (Zaragoza: Ministerio de Educación y Cultura/Instituto «Fernando El Católico»/Diputación de Zaragoza, 1999), 214. 
Narciso de Gabriel contabiliza, no período de 1860 a 1910, a saída de aproximadamente 500.000 pessoas da Galícia, ou seja, um terço dos então habitantes da região. ${ }^{7}$ Para Antón Costa Rico, entre 1836 e 1930, 1.500.000 de galegos deixaram o país. ${ }^{8}$ Mesmo utilizando recortes temporais diferenciados, os números sinalizam que a migração galega foi uma das mais expressivas da Europa no final do século XIX e nas primeiras décadas do XX. Para o Brasil, veio uma parcela significativa desses indivíduos. De acordo com dados oficiais, os espanhóis foram o terceiro maior contingente de imigrantes que aportaram em terras brasileiras, perdendo apenas para os provenientes da Itália e Portugal.

A escassez e a dispersão dos dados estatísticos são desafios enfrentados pelos pesquisadores brasileiros quando se dedicam ao tema da imigração. No caso do Estado de São Paulo, por exemplo, os registros sobre o ingresso de imigrantes, com raras exceções, especificam informações sobre a entrada por períodos mais curtos, o que impede analisar a dinâmica e a intensidade do fluxo migratório das diversas nacionalidades e ou de alguma específica.

Aos estudos sobre a imigração galega no Brasil, acrescentam-se ainda outras dificuldades, que por vezes inviabilizam a detecção desse contingente. A primeira delas refere-se à proximidade linguística. Valéria Gil Condé, ${ }^{9}$ ao analisar a convergência entre o português brasileiro e o galego, identifica como ponto de encontro entre as duas culturas o Norte de Portugal, precisamente as regiões entre o Douro e o Minho, que guardam do ponto de visto histórico-linguístico características da Galícia. As investigações constatam uma certa unidade linguística deste léxico que distingue estas regiões de demais de Portugal e da Espanha. Aliás, de acordo com Luis Felipe de Alencastro e Maria Luiza Renaux, ${ }^{10}$ em Lisboa, os comerciantes lusitanos utilizavam a denominação "galego»

\footnotetext{
7 Gabriel, «Emigración», 1985.

8 Anton Costa Rico, «Con billete de volta. Os americanos da Mariña, a creación de escolas e a búsqueda do progreso», Estudos Migratorios. Revista Galega de Análise das Migracións 1, no. 2 (2008): 131-149.

9 Valéria Gil Condé, «Convergência do léxico por contato entre o português brasileiro e o galego moderno», Labor Histórico 3, no. 2 (2017): 97-107.

${ }_{10}$ Luis Felipe de Alencastro e Maria Luiza Renaux, «Caras e Modos dos Migrantes e Imigrantes», en História da Vida Privada no Brasil, Império: a corte e a modernidade nacional, org. Luis Felipe de Alencastro (São Paulo: Companhia das Letras, 1997), 312.
} 
de forma pejorativa para nomear os portugueses pobres que realizavam trabalhos semelhantes aos feitos pelos emigrados da Galícia.

Como a origem do maior grupo de emigrantes portugueses que chegou às terras brasileiras no período era justamente do Norte de Portugal, podemos considerar assim, como o fez Jorge Fernandes Alves, que parte dos emigrantes galegos ao Brasil saísse da cidade do Porto e não da Espanha. ${ }^{11} \mathrm{O}$ alerta provém da análise que fez sobre a migração intrapeninsular, tomando como fonte os títulos de residência conferidos aos galegos decorrente da convenção consular de 1870 entre Portugal e Espanha. Segundo seus cálculos, em média 2.000 indivíduos solicitaram títulos por ano entre 1874 e 1893. Desconfia, entretanto, que o trânsito de pessoas entre as regiões da Galícia e do Norte de Portugal era mais intenso do que o registrado oficialmente.

Érica Sarmiento da Silva ${ }^{12}$ acrescenta que, no Brasil, era usual a denominação de galegos, tanto para as pessoas naturais da Galícia quanto para os nascidos no Norte de Portugal, corroborada pela circunstância de ambos ocuparem os mesmos ramos profissionais, atuando em atividades de baixa e média qualificação, fosse no comércio, na construção de linhas férreas, na pequena indústria, na construção civil, na atividade portuária, bares, cafés, padaria, dentre outros. Confundidos com a emigração portuguesa, os galegos tornavam-se invisíveis como grupamento social específico. ${ }^{13}$

A esta invisibilidade se associava uma segunda, de acordo com Diana Vidal. ${ }^{14}$ Como as estatísticas de ingresso não discriminavam a proveniência regional dos emigrantes espanhóis, não se podia precisar o contingente galego dentre o total de espanhóis emigrados. Confundiam-se assim, particularmente, galegos e andaluzes: os dois mais importantes agrupamentos étnicos chegados ao Brasil da Espanha. De acordo com

\footnotetext{
11 Jorge Luis Alves, Os brasileiros, emigração e retorno no Porto oitocentista (Porto: Câmara Municipal, 1994), 96-97.

12 Sarmiento Silva, O Outro Rio, 2006.

13 Érica Sarmiento da Silva, «Pelos logradouros cariocas: uma perspectiva da imigração galega no Rio de Janeiro", População e Sociedade. A emigração portuguesa para o Brasil 14/15 (2007): $193-208$. Veja-se também: Regina Weber, «Espanhóis no sul do Brasil: diversidade e identidade», História: Questões \& Debates 56 (2012): 137-157.
}

14 Vidal, «Galícia», 2008. 
Sarmiento da Silva, ${ }^{15}$ entre 1884 e 1939, dos 4.167.301 indivíduos ingressantes em terras brasileiras, apenas 581.718 eram espanhóis. Sabemos pelos dados oferecidos pela Hospedaria do Imigrante em São Paulo que 66\% desses espanhóis, ou seja, 386.085 pessoas, ingressaram pelo Porto de Santos. Mas nem todos se fixaram no estado. Elena Pájaro Peres ${ }^{16}$ estima que dos 143.485 espanhóis que ingressaram em São Paulo entre 1910 e 1914, apenas 108.154 tenham ai se radicado.

Segundo Marília Cánovas, ${ }^{17}$ o subsidio oferecido pelo governo paulista para a compra de passagem a trabalhadores destinados às fazendas de café servia de atrativo a uma população que almejava estabelecer-se na Argentina e no Uruguai. Era em especial o caso dos andaluzes. Outros espanhóis se dirigiram aos demais estados brasileiros, com predileção para Rio de Janeiro, para a Bahia (Salvador) e para o Pará (Belém), onde a bibliografia sobre a temática identifica a existência de grupos de emigrados da Galícia.

Estas digressões sinalizam para dois principais perfis de espanhóis que ingressavam em São Paulo. Por um lado, os andaluzes que se dirigiam às zonas rurais, valiam-se da emigração dirigida ou subsidiada e consideram o Brasil como um local de passagem para atingir a Bacia do Prata. Por outro, os galegos que buscavam as zonas urbanas, faziam uso de seus próprios recursos e contavam com uma extensa rede de solidariedade de compatriotas emigrados, em geral parentes ou vizinhos de suas paróquias. Somente uma pequena parte desse contingente optou por trabalhar nas fazendas de café e nos engenhos de açúcar.

Erica Sarmiento da Silva ${ }^{18}$ delineou o perfil do emigrante galego no período de 1880 e 1939, apontando as seguintes características: a) o percentual de jovens com capacidade produtiva era significativo, 45,2\% dos indivíduos encontravam-se na faixa de 14 a 29 anos; 39,2\% dos indivíduos encontravam-se na faixa etária de 30 aos 49 anos, o que somado chega a $84,6 \%$; b) os emigrantes na maioria eram homens, somente $12 \%$ eram mulheres; c) o índice de alfabetismo era bastante alto, 88,3\% dos

\footnotetext{
15 Sarmiento Silva, O Outro Rio, 2006.

16 Pájaro Peres, A inexistência da Terra Firme, 2003, 34.

17 Cánovas, «Imigrantes», 2005.

${ }_{18}$ Sarmiento Silva, O Outro Rio, 2006.
} 
emigrantes sabiam assinar o nome. ${ }^{19}$ Segundo Narciso de Gabriel, ${ }^{20}$ entre 1860 e 1940, as taxas de alfabetização masculina na Galícia saltaram de 33 para 71\%, configurando-se em uma importante estratégia de emigração por parte das famílias.

Peña Saavedra ${ }^{21}$ e Costa Rico ${ }^{22}$ apontam que os emigrantes, individual ou coletivamente, realizaram intervenções no campo escolar tanto nos países para os quais se dirigiram, quanto nos lugares de origem. As motivações que os impulsionaram, principalmente os indianos - americanos, a investir na educação articulavam-se em dois grupos de fatores. $\mathrm{O}$ primeiro era de ordem mais geral e permanente no tempo, reunia indivíduos que valorizavam positivamente a educação e tinham tendência filantrópica, altruísta e caritativa. O segundo grupo exibia móveis mais específicos e variáveis de acordo com os sujeitos e o contexto, como a devoção religiosa, que era tanto mais forte quando recuamos no tempo e mais fraca quando avançamos para o presente; expectativas de rentabilidade social, econômica e/ou espiritual da contribuição realizada, o desejo de imortalizarem-se na memória das pessoas, junto com a esperança de retorno simbólico ao lugar de origem.

As escolas criadas pelos emigrantes na Galícia constituíam-se em construções humildes, com 3 ou 4 salas, a graduação em séries era incipiente, e contavam com poucos meios didáticos. Instalavam-se em lugares onde não houvesse oferta de instrução. Costa Rico ${ }^{23}$ aponta que excepcionalmente, os centros culturais/escolas construídos fugiam a esta regra, pois em muitas outras ocasiões, o centro e as salas de aula eram, de fato, um espaço cultural e educacional importante e moderno. ${ }^{24}$

A emigração galega, assim, acabou impactando ou impulsionando a difusão da alfabetização na região rural da Galicia. Essa experiência

\footnotetext{
${ }^{19}$ Em estudo que comparava as migrações galega e portuguesa para o Brasil no período, Diana Vidal demonstrou que também com relação ao sexo, idade e índice de alfabetização os perfis se assemelhavam. Cf. Vidal, «Galicia», 2008.

${ }_{20}$ Narciso de Gabriel, Ler e escribir en Galicia (A Coruña: Universidade da Coruña, 2006), 57.

${ }^{21}$ Peña Saavedra, «As escolas», 2002.

22 Costa Rico, «As sociedades», 1990.

${ }^{23}$ Anton Costa Rico, «Emigrantes», 2008, 13-45.

${ }^{24}$ Antón Costa Rico, «Ignacio Ares de Parga e as "escolas dos americanos" en Galicia», Pontevedra. Revista de estudios provinciais 15 (1999): 145
} 
marcou de forma significativa o desenvolvimento cultural e educativo da região e as pessoas diretamente envolvidas nas atividades empreendidas, pois como assinala Malheiro Gutiérrez, as escolas fundadas pelas chamadas associações educacionais nasceram como verdadeiros ateneus da cidadania, introduzindo novas atitudes e valores cívicos, de acordo com as sociedades democráticas americanas modernas, enriquecendo os comportamentos tradicionais existentes de coexistência comunitária. ${ }^{25}$ Castrillo Sagredo ${ }^{26}$ indica que esse processo também ocorreu com os emigrantes de outras partes da Espanha, tais como Astúrias, Santander, dentre outras. No entanto, o fenômeno foi muito mais intenso na Galícia.

A partir de 1840, surgiram instituições beneméritas, de âmbito nacional como a Sociedad de Beneficencia Española de Tampico, em Tampico, México, ou de âmbito regional, a Sociedad de beneficencia de Naturales de Cataluña, em Havana, Cuba. Emergiram nos vários países latino-americanos onde os galegos estavam presentes. Peña Saavedra ${ }^{27}$ assinala que tais instituições poderiam ser classificadas de acordo com suas abrangências territoriais: a) as macroterritoriais que agrupavam os emigrantes por comunidades regionais; b) as microterritoriais, que reuniam os emigrantes localmente; c) as mesoterritoriais, que agregavam os emigrantes de uma única região ou província. A função da educação escolar passou a ser incorporada pelas sociedades macroterritoriais a partir de 1870. As principais sociedades criadas nesse período e que serviram de modelo para outras comunidades foram as das cidades de Montevidéu (1876) e de Buenos Aires (1877). No entanto, o Centro Galego de maior expressão e projeção foi o de Havana.

Para entender como essas associações atuaram no Brasil, na sua relação com a educação, tomemos o exemplo do Centro Español de Santos.

\footnotetext{
${ }_{25}$ Xosé Manuel Malheiro Gutiérrez, «Emigration and education. Galician emigration to America and its impact on the processes of literacy, schooling and civic education amongst the rural and seafaring popular clases», History of Education 47, no. 6, (2018): 761.

${ }^{26}$ Benito Castrillo Sagredo, El aporte de los «indianos» a la Instrucción Pública, a la Beneficencia y al Progreso general de España y su historia (Buenos Aires: Prensa de Buenos Aires, 1926).

27 Vicente Peña Saavedra, Éxodo, organización comunitaria e intervención escolar: la impronta educativa de la emigración transoceánica (Santiago de Compostela: Xunta da Galicia, 1991).
} 


\section{CENTRO ESPAÑOL DE SANTOS: PRODUÇÃO DE UMA IDENTIDADE SOCIAL HIBRIDA}

Elda Gonzalez Martinez ${ }^{28}$ afirma, com base no Inventário de Interesses Demográficos, de 1933, e em informações oferecidas pelo consulado, que a emigração galega estava bem disseminada em São Paulo. A maior concentração populacional encontrava-se na região de Araraquara (Catanduva, Rio Preto, Arara, Santa Adélia) com aproximadamente 108.000 migrantes. Na região central (Campinas, Sorocaba), havia aproximadamente 28.000 indivíduos. No noroeste do Estado (Bauru, Araçatuba e Marília), estimava-se 45.000 e, em São Carlos, 8.000. Na cidade de Santos, pelo Censo de 1913, dos 39.802 residentes, 8.343 eram espanhóis, dentre eles $78 \%$ galegos. Segundo o consulado, as principais ocupações profissionais dessa população eram as docas e o comércio.

Os espanhóis criaram muitas associações em São Paulo, cuja característica comum era a fragilidade financeira devido ao pequeno número de associados. Em Santos, no mesmo período da criação do Centro Español foram fundadas, também por espanhóis, a Sociedade Española de Repatriación (1902), com o objetivo auxiliar no retorno à Espanha aos sócios que estivessem quites com as mensalidades; e a Sociedade Española de Socorros Mútuos e Instrucción (1900), que estabelecia convênios com hospitais e médicos para oferecer atendimento aos associados. Além das sociedades beneficentes, na cidade houve algumas mutualistas, que não tinham recorte étnico, como a Sociedade Humanitária dos Empregados do Comércio (1879); a União Operária (1890), fundada por trabalhadores da construção civil; a Sociedade Beneficente 2 de Fevereiro (1902); e a Associação Feminina Beneficente e Instrutora (1902).

Marília Cánovas ${ }^{29}$ destaca que foi, sobretudo, no Estado de São Paulo, onde o associativismo espanhol foi mais expressivo, principalmente no final do século XIX e início do XX, marcado pelo modelo mutualista difundido em países como a Argentina e Uruguai. A autora, ainda,

\footnotetext{
28 Elda González Martínez, «Café, inmigración y estructura urbana Sao Paulo en el siglo XIX y principios del XX», Anuario de estudios americanos 54, no. 2 (1997): 593-611.

${ }_{29}$ Marília Dalva Kaulmann Cánovas, Imigrantes Espanóis na Paulicéia: trabalho, sociabilidade Urbana (1890-1922) (Doutorado, FFLCH-USP, 2007), 299.
} 
aponta que, segundo Alejandro Fernández, ${ }^{30}$ investigador de modelos de associativismo espanhol desse período em diversos países americanos, somente uma minoria dos espanhóis ingressantes na América conhecia a experiência associativa ou havia tomado parte em alguma associação na Espanha.

O Centro Español de Santos pode ser compreendido no âmbito dessas iniciativas. ${ }^{31}$ Como afirmando anteriormente, foi criado em janeiro de 1895. Sua primeira denominação foi «Casino Español, que rapidamente mudou o nome para Centro Español e hoje é conhecido como Centro Español y Repatriación de Santos, devido à sua fusão com a Sociedad Española de Repatriación».32 A primeira Junta Diretiva constituía-se por:

Presidente: Manuel Troncoso 33 ; Vice-Presidente: Justino Flores Fernández; Secretario: Gerardo Santiago Álvarez; Vice-secretário: José V. Bojart; Tesoureiro: Juan Estévez Martínez; Contador: José María Molinos; Procuradores: D. Antonio Vázquez Quintela, D. Manuel Alonso Fernández, D. Felipe Vidal Ribas; Vocales: D. Guillermo Linares, D. Eduardo Parada, D. Francisco Gimeno, D. José Rodríguez Pérez, D. Segundo Lobariñas, D. Juan V. Bojart, D. Francisco Gómez Fernández, D. José Fernández

\footnotetext{
${ }^{30}$ Alejandro Fernández, «El mutualismo español en un barrio de Buenos Aires: San José de Flores, (1890-1900)», en Asociacionismo, trabajo e identidad étnica. Los italianos en América Latina en una perspectiva comparada, comp. Fernando J. Devoto y Eduardo J. Míguez (Buenos Aires: CEMLACSER-IEHS, 1992), 169-188.

31 Diana G. Vidal y Maurilane Biccas, «As múltiplas estratégias de escolarização do social em São Paulo (1770-1970). Cultura e prática escolares», en Educação e Reforma: o Rio de Janeiro nos anos 1920-1930, org. Diana Gonçalves Vidal (Belo Horizonte: Argvmentvm, 2008): 19-44.

32 Karime Antigo y Diana G. Vidal, «A imigração galega em santos: associações de socorros mútuos e repatriação (1870-1920)», en Santos na modernidade capitalista (1870-1930): novas abordagens e releituras de velhas fontes, coords. Luiz Henrique Portela Faria y Maria Apparecida Franco Pereira (São Paulo: e-Manuscrito, 2019), 147-174.

33 Troncoso e Cividanes são sobrenomes comuns nas terras do Baixo Miño galego, fronteiriças com o Alto Minho português. Na vila de Goián é muito frequente o sobrenome Troncoso (de procedência lusa) e provavelmente este Troncoso era natural dessa vila. Em Santos, os migrantes goianeses fundaram a denominada Sociedad de Socorros y Mejoramientos en el pueblo de Goyán en 1935, que chegou a contar com 200 sócios. Da relativa importancia da comunidade goianesa em Santos também dá conta Eliane Veiga Porta ao citar a «Sociedade de Obreros Agricultores, de Goyan» entre as muitas entidades espanholas que «enviaram seu estatuto, ou somente uma correspondência amigável ao Centro Espanhol, ou ainda comunicaram a posse de nova diretoria» em 1905 (Elaine Veiga Porta, Os imigrantes, p. 101). Possivelmente, a afinidade local do presidente Manuel Troncoso explica a nota de correspondencia da Sociedade de Obreros y Agricultores de Goyán.
} 
Domínguez, D. José Souto Domínguez, D. Rufino Fernández, D. Antonio Araujo, D. Juan Antonio Cividanes; Bibliotecario: D. José Pascual Gómez; Síndicos: D. Antonio Alonso Fernández, D. Miguel García, D. Miguel Vázquez.

Eram na sua maioria galegos, como atesta a investigação de Marília Cánovas, ${ }^{34}$ provavelmente naturais de Pontevedra, estabelecidos financeiramente na cidade.

Um mês após a criação do Centro Español, em reunião ocorrida no dia 14 de fevereiro, era anunciado o projeto de adquirir e construir uma sede própria. Em 14 de março um terreno de 750 metros quadrados foi comprado à Rua Andrade, no bairro de Paquetá, e em 02 de maio celebrou-se a pedra inaugural. O dinheiro para a construção da sede veio de várias fontes, como empréstimos junto aos associados por meio de ações, doação de materiais, dentre outras. Durante todo o período da construção, uma comissão ficou responsável pela compra de telhas, ladrilhos e madeira. Nas atas anuais, incluía-se o detalhamento de todas as atividades envolvidas na construção, bem como divulgavam-se os agradecimentos a todos os participantes. A ata de 1895 contabilizava 147 doações, feitas por associados e outras pessoas não identificadas.

Finalizada a obra, a sede do Centro foi instalada em um prédio majestoso para o padrão da época. Ao projeto original foi acrescido um anoxe para acolher um teatro e uma escola. A Junta Diretiva comemorava o fato de ser uma das primeiras sociedades de espanhóis no Brasil a ter uma sede própria. A construção pretendia suscitar o sentimento de pertencimento a um grupo, a uma coletividade. De acordo com Porta, ${ }^{35}$ o Centro ganhou destaque na cidade por ter uma sede com instalações adequadas para reuniões e comemorações, o que se evidenciava pelas solicitações de sociedades para empréstimo de salões, palco cênico, piano, cadeiras, dentre outras, surgidas após 1903.

A identidade social do Centro foi se consolidando por meio do espaço, por meio do lugar ocupado na cidade e das relações que nutriu com outras sociedades e associações em Santos, no âmbito do Estado de São

\footnotetext{
34 Marilia Cánovas, Santos e imigração na bèlle époque (São Paulo: Edusp, 2017): 271-278.

35 Porta, Os imigrantes, 2008, 95.
} 
Paulo e, mesmo, no Brasil. Isto pode ser observado pelas menções e agradecimentos registrados nos Livros de Memória.

Outras ações também visavam promover o senso de pertencimento a uma coletividade, como a criação de uma escola e a organização de uma biblioteca. Consubstanciavam o que no Estatuto emergia como as bases do associativismo: "reunir lo ameno y lo agradable á benéfico y provechoso, á fin de fomentar el espíritu de asociación que une á los sagrados vínculos de la fraternidad y la armonía, ya para instruirse, ya para ajudarse mutuamente». ${ }^{36}$

Detalhando inciativas com finalidade de fomentar tal espírito, o Estatuto trazia diretrizes para o funcionamento de uma seção de recreação e instrução, bem como continha capítulos específicos sobre a constituição de uma biblioteca e sobre obras de socorros mútuos.

Em 1903, na ata elaborada sobre a assembleia do Centro Español, figurava a discussão e o anúncio da formação de uma escola:

O Reglamento Escolar presentado por la Comisión al efecto nombrada, y se delibero: realizar um espectáculo cujo producto seria aplicado á la adqusición de utensílios y muebles escolares, y anunciar por médio de la prensa local y La Voz de España, de S. Pablo, la apertura de las matrículas para las aulas inauguradas el 15 de setiembre. ${ }^{37}$

Entretanto, seu início deu-se efetivamente em 1904,38 permanecendo em atividade até o final de 1906. Nos Livros de Memória, aparecem referências às atividades educacionais voltadas para adolescentes e adultos, com a instauração de aulas noturnas e o desejo de criar uma escola diurna. No regimento interno da Sociedade Centro Español de Santos, no capítulo dedicado ao Colégio Social, definiram-se os critérios para as matrículas de sócios e de seus filhos menores de 15 anos e maiores de 7 anos, facultando-se aos estrangeiros interessados que fizessem uma

\footnotetext{
${ }_{36}$ Centro Español. Estatutos de la Sociedad Centro Español de Santos fundado em 06 de enero de 1895. (São Paulo: Typografia de La Voz da España, 1895).

${ }_{37}$ Centro Español. Libro de Memorias del ejercicio de 1903. (São Paulo: Typografia de La Voz de España, 1903).

38 Maurilane de Souza Biccas, A história da Escolarização de Adolescentes e Adultos no Brasil (1870195º) (Tese de Livre Docência, FEUSP, 2019).
} 
solicitação à Junta Diretiva. Os alunos deveriam apresentar os documentos de identidade e certificado de vacina. A matrícula era gratuita para o curso primário e, para os outros cursos, os alunos deveriam pagar uma taxa de $10 \$ 000$ no ato da inscrição. Os recursos financeiros advindos das matrículas eram revertidos para a aquisição de objetos e materiais escolares e para premiação dos alunos classificados pela frequência e bom comportamento.

Novamente em 1911, encontramos o registro da reabertura das aulas, mantendo-se em funcionamento até 1917, de acordo com a pesquisa de mestrado, em andamento, de Karime Antigo. No escopo deste artigo, entretanto, detalharemos apenas o primeiro período de atuação da escola do Centro Español, entre 1904 e 1906, tomando como fonte os Livros de Memória elaborados pela associação.

A escola iniciou suas atividades com 41 alunos matriculados (28 sócios e 13 não sócios), oferecendo matrículas para o ensino primário (22 alunos); debujo (18 alunos); castelhano (09 alunos); aritmética (08 alunos); francês (03 alunos); latim e geografia (1 aluno). Durante todo o período, esteve como professor da escola o galego Juan Bernils, que de acordo com Cánovas, ${ }^{39}$ havia ingressado como sócio no Centro em 1903.

No Livro de Memória, publicado em 1905, fazendo um balanço da instrução promovida em 1904, Juan Bernils demonstrava desanimo pela baixa procura e frequência:

las clases que nos figurábamos a transbordar de sedentos de algo a saber, las temos presenciado casi em absoluto desiertas, sendo el profesor obligado a retirar-se noches consecutivas por el diminuto número de alumnos que concurrian. ${ }^{40}$

A exceção eram as aulas de desenho, uma matéria de adorno y serviendo, las más de las veces, de distracción al espíritu fatigado por extenuante struglle for life, el dibujo há tenido durante todo el curso extraordinária concurrencia, sendo raro el

\footnotetext{
39 Cánovas, Santos, 309.

40 Centro Español. Libro de Memorias del ejercicio de 1904. (São Paulo: Typografia de La Voz de España, 1904).
} 
dia, y esto por culpa exclusiva del profesor, que la clase respectiva la dejado de funcionar. ${ }^{41}$

As informações sobre o funcionamento em 1905 apontam que se matricularam 29 pessoas: no curso de debujo (18 alunos); aritmética e castelhano (15 alunos); primário (4 alunos); francês (3 alunos) e latim (1 aluno). Apesar da pouca procura e frequência nos cursos oferecidos, o Livro de Memória de 1907 apresenta a proposta aprovada na assembleia dos sócios, realizada no final de 1906, para a ampliação da secção de instrução aos filhos dos sócios e não sócios, inauguração de aulas diurnas e aprimoramento da escola noturna.

Em 1906, estavam matriculados 53 alunos, distribuídos nos seguintes cursos: debujo (37 alunos); aritmética (31); português e castelhano (13 alunos em cada); primário (7 alunos) e latim (1 aluno). No Livro de Memória de 1907, aparece pela primeira vez a idade dos alunos, de 09 aos 34 anos, sendo que 30\% na faixa etária de (9 aos 15 anos); 24\% na faixa etária de (16 aos 20 anos); 15\% de (21 aos 25 anos); $26 \%$ na faixa etária de 26 aos 30 anos e 5\% na faixa etária de 31 aos 35 anos.

As razões do encerramento da escola ainda nos escapam. Podem referir-se à baixa frequência, seguidamente mencionada pelo professor Juan Bernils. As fontes não nos permitem avançar. No entanto, sabemos da reabertura da função em 1911. Ou seja, podemos dizer que tratou-se de uma interrupção temporária, permanecendo a preocupação com a educação escolar no seio dos objetivos do Centro Español.

O Centro também mantinha uma biblioteca, até a presente data em funcionamento. Não fugia às características comuns às escolas americanas, como afirma Malheiro Gutiérrez..$^{42} \mathrm{O}$ estabelecimento da biblioteca também pode ser compreendido como uma maneira de afirmar e construir uma identidade social, o que pode ser percebido pela maneira como o acervo foi constituído. Nos Livros de Memórias de 1903, 1904 e 1907 há informações sobre os periódicos incorporados, indicando local de publicação, conforme o Quadro:

\footnotetext{
${ }^{41}$ Centro Español. Libro de Memorias, 1904.

${ }_{42}$ Malheiro Gutiérrez, Mobilización, 7.
} 
Tabla 1 - Lista dos periódicos da Biblioteca do Centro Español (1903-1904-1907)

\begin{tabular}{|c|c|c|c|c|}
\hline Periódicos & Local de publicação & 1903 & 1904 & 1907 \\
\hline $\begin{array}{l}1 \text { - La Ilustración Española y } \\
\text { Americana }\end{array}$ & Madrid & $\operatorname{sim}$ & $\operatorname{sim}$ & Sim \\
\hline $2-A B C$ & Madrid & Sim & Sim & Sim \\
\hline 3 - El Liberal & Madrid & Sim & Sim & Sim \\
\hline 4 - El Imparcial & Madrid & Sim & Sim & Sim \\
\hline 5 - Mercurio & Barcelona & Sim & Não & Sim \\
\hline 6 - El Mundo Latino & Madrid & Sim & Não & Sim \\
\hline 7 - El Faro de Vigo & Vigo & Sim & Não & Não \\
\hline 8 - Caras y Caretas & Buenos Aires & Sim & Não & Não \\
\hline 9 - Jornal do Brasil & Rio de Janeiro & Sim & $\operatorname{sim}$ & Não \\
\hline 10 - Revista da Semana & Rio de Janeiro & Sim & Sim & Não \\
\hline 11 - El Correo Español & Rio de Janeiro & Sim & Não & Não \\
\hline 12 - El Correo Gallego & Rio de Janeiro & Sim & Sim & Não \\
\hline 13 - El Progresso Sul Americano & Buenos Aires & Sim & Não & Não \\
\hline 14 - O Correio Paulista & São Paulo & Sim & Sim & Não \\
\hline 15 - O Estado de São Paulo & São Paulo & Sim & Não & Não \\
\hline 16 - A Tribuna & Santos & Sim & Sim & Sim \\
\hline 17 - A Cidade de Santos & Santos & Sim & Sim & Sim \\
\hline 18 - La Voz de España & São Paulo & Sim & Sim & Sim \\
\hline 19 - El Támega & Ourense & Não & Sim & Não \\
\hline 20 - Revista Kosmos & Buenos Aires & Não & Sim & Sim \\
\hline 21 - O Nuporanga & Nuporanga/S. Paulo & Não & Não & Sim \\
\hline 22 - Herald Guardia & Estados Unidos & Não & Não & Sim \\
\hline 23 - Diario de Santos & Santos & Não & Não & Sim \\
\hline 24 - Wett Connier & Alemanha & Não & Não & Sim \\
\hline $25-O$ Verso & Santos & Não & Não & Sim \\
\hline 26 - Onze de Agosto & São Paulo & Não & Não & Sim \\
\hline
\end{tabular}


A maioria desses periódicos oferecia assinaturas gratuitas para a biblioteca do Centro. Podemos observar que há jornais da região da Galícia -El Támega (Ourense) e El Faro de Vigo (Vigo-Pontevedra)_-, e provenientes das cidades de Madrid e de Barcelona. Outras três assinaturas referem-se a jornais de Buenos Aires. Encontram-se ainda um jornal da Alemanha e outro dos Estados Unidos. Mais de 50\% das assinaturas, entretanto, consistem de jornais brasileiros, sendo que três deste conjunto são publicados por galegos/espanhóis. O próprio nome dos periódicos já anuncia: El Correo Español, El Correo Gallego e o La Voz de España, do Rio de Janeiro e de São Paulo.

A biblioteca do Centro Español tinha por propósito ser um espaço de socialização, de estudos e de lazer. Ter periódicos com notícias do país, da região de origem dos associados, trazia a possibilidade aos que aportavam em Santos de manter algum contato com conhecidos, parentes, familiares que seguiam a vida na Espanha. No que se refere aos jornais comerciais brasileiros, principalmente de Santos e de São Paulo, também eram de leitura necessária para acompanhar os acontecimentos cotidianos, bem como o cenário político, econômico e social do país receptor. Os jornais publicados no Brasil, mas identificados com a Espanha e a Galícia, remetiam à profissão de muitos dos emigrados, relacionada às empresas gráficas. Cabe mencionar que o Centro Español construiu uma relação mais estreita com dois jornais, a Tribuna de Santos e La Voz de España, cujas tipografias passaram a imprimir as atas - Livros de Memórias- já nos primeiros anos da década de 1900.

Por fim, sobre os livros que compunham o acervo da biblioteca do Centro, temos apenas informações acerca de idiomas, número de livros e quantidade de volumes conforme o Quadro abaixo, em que se percebe um equilíbrio entre as incorporações em português e em espanhol.

Tabla 2 - Obras existentes na Biblioteca - 1903, 1904, 1905 e 1907

\begin{tabular}{|l|c|c|c|c|c|c|c|c|}
\hline \multirow{2}{*}{ Idioma } & \multicolumn{2}{|c|}{1903} & \multicolumn{2}{c|}{1904} & \multicolumn{2}{c|}{1905} & \multicolumn{2}{c|}{1907} \\
\cline { 2 - 10 } & Obras & Volumes & Obras & Volumes & Obras & Volumes & Obras & Volumes \\
\hline Português & 257 & 366 & 286 & 420 & 295 & 432 & 313 & 453 \\
\hline Espanhol & 137 & 177 & 163 & 207 & 173 & 240 & 259 & 365 \\
\hline Frances & 95 & 123 & 97 & 125 & 97 & 125 & 97 & 125 \\
\hline
\end{tabular}


Tabla 2 - Obras existentes na Biblioteca - 1903, 1904, 1905 e 1907 (cont.)

\begin{tabular}{|l|r|r|r|r|r|r|r|r|}
\hline \multirow{2}{*}{ Idioma } & \multicolumn{2}{|c|}{1903} & \multicolumn{2}{c|}{1904} & \multicolumn{2}{c|}{1905} & \multicolumn{2}{c|}{1907} \\
\cline { 2 - 9 } & Obras & Volumes & Obras & Volumes & Obras & Volumes & Obras & Volumes \\
\hline Inglês & 60 & 64 & 60 & 64 & 60 & 64 & 60 & 64 \\
\hline Italiano & 4 & 4 & 4 & 4 & 4 & 4 & 4 & 4 \\
\hline Alemão & 2 & 2 & 4 & 4 & 4 & 4 & 4 & 4 \\
\hline Latim & 1 & 1 & 3 & 3 & 3 & 3 & 3 & 3 \\
\hline Grego & 0 & 0 & 1 & 1 & 1 & 1 & 1 & 1 \\
\hline Total & 556 & 737 & 618 & 808 & 637 & 873 & 741 & 1091 \\
\hline
\end{tabular}

Uma análise mais detalhada dos títulos permitiria avançar na caracterização desse empreendimento. No entanto, a falta dessa investigação não invalida afiançar a preocupação educativa manifesta pelos membros do Centro Español na constituição da biblioteca. Além de servir à instrução dos sócios, como previsto no Estatuto, era lugar de convívio e lazer. Outras iniciativas como palestras, encenação de peças de teatro, festas e saraus foram promovidas e tinham como objetivo estreitar laços sociais e fomentar «vínculos de la fraternidad y la armonía, ya para instruirse, ya para ayudarse mutuamente»,43 evidenciando o interesse em encorajar a formação e a manutenção do sentimento de pertencimento a uma determinada coletividade.

\section{COMENTÁRIOS FINAIS}

Porta $^{44}$ sistematizou informações sobre a origem dos espanhóis associados ao Centro Español de Santos no período de 1895 a 1920, a partir de dados obtidos no Livro de Registros de Associados: 44,49\% dos sócios provinham da região da Galícia; 9,85\% vinham de outras províncias da Espanha; e 43,04\% não identificaram a origem. Entre os estrangeiros figuravam portugueses $(0,55 \%)$, italianos $(0,21 \%)$, argentinos $(0,07 \%)$ e brasileiros $(1,85 \%)$.

\footnotetext{
${ }^{43}$ Centro Español. Estatutos, 1895.

44 Porta, Os imigrantes, 126.
} 
Cánovas ${ }^{45}$ afirma que os integrantes a primeira Junta Diretiva eram provavelmente galegos naturais de Pontevedra, estabelecidos financeiramente na cidade de Santos. A bibliografia existente sobre a migração étnica para o Brasil sinaliza para a existência de grupos de emigrados galegos na Bahia, no Pará e no Rio de Janeiro, como já anunciado, e para a publicação de periódicos étnicos, como El Correo Gallego, no Rio de Janeiro.

Apesar de todos estes índices, em nenhum momento a associação criada em Santos tomou o genitivo galego para identificar-se. Denominou-se Casino Español, Centro Español e, atualmente, Centro Español y Repatriación de Santos. Curiosamente, nunca declinou da grafia em espanhol para o nome da entidade reforçando um pertencimento mais à Espanha que à Galícia propriamente dita. Aliás, cabe ressaltar que nas disciplinas ensinadas na escola, durante o curto período analisado, encontramos apenas menção a aulas de castellano. Simultaneamente, os Livros de Memória valem-se do idioma principalmente espanhol para sua escrita.

No primeiro apartado deste artigo, procuramos demonstrar uma dupla invisibilidade galega quando se aborda a emigração desse contingente ao Brasil, atentando à proximidade entre galegos e portugueses no Norte de Portugal, à convergência entre o português brasileiro e o galego e à precariedade das estatísticas no que concerne aos grupos étnicos da Espanha que ingressaram em terras brasileiras. Talvez ao reforçar elementos da cultura espanhola, o Centro Español de Santos buscasse distinguir-se de portugueses e brasileiros, e constituir uma nova identidade nem propriamente galega, nem totalmente espanhola.

Esta foi a razão porque evitamos aqui a referir-nos a uma identidade galega. Preferimos operar com a noção de uma identidade social hibrida, compósita de valores e sentimentos associados ao ultramar, mas tramada nas condições concretas da sobrevivência nas novas terras por parte de indivíduos e grupos. Perscrutar os meandros dessa construção suscita insistir na investigação, abrindo perspectivas de análise não encerradas no olhar retroativo que entende as identidades étnicas como encapsuladas nos países de origem. Mas, ao contrário, percebe-as como (re)configuradas no entroncamento entre o passado e a expectativa de futuro, vivenciadas individual e coletivamente pelos sujeitos nesse trânsito entre mundos.

45 Cánovas, Santos, 271-278. 


\section{Nota sobre as autoras}

Maurilane de Souza Biccas é professora Livre Docente em História da Educação na Faculdade de Educação da USP (2019). Compõe a Comissão de Cooperação Nacional e Internacional da FEUSP (CCInt-FE). Coordena dois convênios internacionais, Universidade Pedagógica em Moçambique e o da Faculdade de Ciências Sociais e Humanas da Universidade Nova de Lisboa, Portugal. Desde 2002, compõe a coordenação do NIEPHE (Núcleo Interdisciplinar de Estudos e Pesquisas em História da Educação). Possui graduação em Psicologia pela Faculdade Mineira de Educação e Cultura (1983), mestrado em Educação pela Universidade Federal de Minas Gerais (1995), doutorado em Educação pela Universidade de São Paulo (2001) e pós-doutorado em Educação pela Universidade de Santiago de Compostela (2009). Foi editora da Revista Brasileira de História da Educação no período de 2004 a 2007. Atuou no período de 2006 a 2012, pela ALFASOL e o Ministério das Relações Exteriores, como assessora junto ao Ministério da Educação de São Tomé e Príncipe, na África. Participou também como assessora via SECADI e Ministério da Educação do Brasil junto ao Ministério do Desenvolvimento Humano de Moçambique, no período de 2015 a 2016. Compôs a comissão de Editores Assistentes da Educação e Pesquisa, revista da Faculdade de Educação da Universidade de São Paulo. Tem experiência na área de Educação, com ênfase em História da Educação, atuando principalmente nos seguintes temas: imprensa pedagógica, práticas escolares, cultura escolar e escolarização, educação de pessoas jovens e adultas.

Diana Vidal é professora titular em História da Educação na Faculdade de Educação (USP) (2010), diretora do Instituto de Estudos Brasileiros (USP) (2018-2022), bolsista Produtividade em Pesquisa do CNPq nível 1B, membro do Comitê Executivo da ISCHE (International Standing Conference for the History of Education) (2014-2020), editora chefe da Global Histories of Education, coleção criada pela ISCHE em colaboração com a Palgrave Macmillan e, a partir de 2018, Tesoureira da mesma associação internacional, membro do International Advisory Board of the British Journal for Educational Studies (BJES) (2019-2021) e Editora Senior da Oxford Research Encyclopedia of Education. É lider do Projeto Temático FAPESP Saberes e práticas em fronteiras: por uma 
história transnacional da educação (1810-...) (processo nr. 2018/266994). Defendeu sua livre-docência em História da Educação em 2005. Possui graduação em História pela Universidade do Vale do Paraíba (1985), mestrado em História pela Universidade Estadual de Campinas (1990), doutorado em Educação pela Universidade de São Paulo (1995) e pós-doutorado em Educação no INRP-França (2001) e na Universidade de Santiago de Compostela (2007). Desde 1996, exerce a coordenadoria do Núcleo Interdisciplinar de Estudos e Pesquisas em História da Educação (NIEPHE). Foi vice-diretora da Faculdade de Educação da USP (2014-2018). Foi presidente da Sociedade Brasileira de História da Educação (2003-2007). Tem experiência na área de Educação, com ênfase em História da Educação, atuando principalmente com os seguintes temas: história transnacional da educação, cultura escolar, escola nova, práticas escolares de leitura e escrita, historiografia e circulação internacional de modelos e práticas pedagógicas.

\section{REFERÊNCIAS}

Alencastro, Luis Felipe de y Maria Luiza Renaux. «Caras e Modos dos Migrantes e Imigrantes». En História da Vida Privada no Brasil, Império: a corte e a modernidade nacional, organizada por Luis Felipe de Alencastro, 291-336. São Paulo: Companhia das Letras, 1997.

Alves, Jorge Luis. Os brasileiros, emigração e retorno no Porto oitocentista. Porto: Câmara Municipal, 1994.

Antigo, Karime y Diana Vidal. «A imigração galega em santos: associações de socorros mútuos e repatriação (1870-1920)». En Santos na modernidade capitalista (1870-1930): novas abordagens e releituras de velhas fontes, organizada por Luiz Henrique Portela Faria y Maria Apparecida Franco Pereira, 147-174. São Paulo: e-manuscrito, 2019.

Biccas, Maurilane de Souza. «A história da Escolarização de Adolescentes e Adultos no Brasil (1870-1950)». PhD dis., Universidade de São Paulo, 2019.

Cánovas Marília Dalva Kaulmann. «Imigrantes Espanóis na Paulicéia: trabalho, sociabilidade Urbana (1890-1922)». PhD dis., Universidade de São Paulo, 2007.

Cánovas, Marilia Dalva Kaulmann. Santos e imigração na bèlle époque. São Paulo: Edusp, 2017.

Cánovas, Marília Dalva Klaumann. «Imigrantes espanhóis na cafeicultura paulista, 1880-1930: protagonistas ou coadjuvantes». Revista História Hoje. Revista eletrônica de história 2, no. 6 (mar. 2005): 1-16. 
Cánovas, Marília Dalva Klaumann. «A emigração espanhola e a trajetória do imigrante na cafeicultura paulista: o caso de Villa Novaes, 1880-1930».Mestrado: FFLCH-USP, 2001.

Castrillo Sagredo, Benedito. El aporte de los «indianos» a La Instrución Pública, a la Beneficencia y al Progresso general de España y su historia. Buenos Aires: Prensa de Buenos Aires, 1926.

Condé, Valéria Gil. «Convergência do léxico por contato entre o português brasileiro e o galego moderno». Labor Histórico 3, no. 2 (2017): 97-107.

Costa Rico, Antón. "As sociedades dos “Americanos" e a educación em Galicia». Revista da Comisión Galega do Quinto Centenario 5 (1990): 89-140.

Costa Rico Antón. "Ignacio Ares de Parga e as "escolas dos americanos" . Pontevedra. Revista de estudios provinciais 15 (1999): 145.

Costa Rico, Antón. «Emigrantes, escuelas y regeneración social: los emigrantes gallegos a América y el impulso a la educación (1879-1936)». Revista Brasileira de Historia da Educação 16 (2008): 13-45.

Costa Rico, Anton. "Con billete de volta: os americanos da Mariña, a creación de escolas e a busca do progreso». Estudos Migratorios: Revista Galega de Análise das Migracións 1, no. 2 (2008), p. 131-149.

Fernández, Alejandro. «El mutualismo español en un barrio de Buenos Aires: San José de Flores, (1890-1900)». En Asociacionismo, trabajo e identidad étnica. Los italianos en América Latina en una perspectiva comparada, compilado por Fernando J. Devoto y Eduardo J. Míguez, 169-188. Buenos Aires: CEMLA-CSER-IEHS, 1992.

Gabriel, Narciso de. «Emigración y alfabetización en Galicia». Historia de la educación 4 (1985): 321-336.

Gonzalez Martínez, Elda. "Café, inmigración y estructura urbana Sao Paulo en el siglo XIX y principios del XX». Anuario de estudios americanos 54, no. 2 (1997): 593-611.

Klein, Herbert S. A imigração espanhola no Brasil. São Paulo: Editora Sumaré / FAPESP, 1994.

Malheiro Gutiérrez, Xosé Manuel. «Mobilización societária, correntes de pensamento e escolas de emigrantes em Galicia durante o primeiro Tércio do século XX: o protagonismo de Ignácio Ares de Parga e Anton Alonso Rios». PhD diss., Universidad de Santiago de Compostela, 2003.

Malheiro Gutiérrez, Xosé Manuel. «Emigration and education. Galician emigration to America and its impact on the processes of literacy, schooling and civic education amongst the rural and seafaring popular clases». History of Education 47, no. 6 (2018): 741-762.

Pájaro Peres, Elena. A inexistência da Terra Firme: A imigração Galega em São Paulo, 1946-1964. São Paulo: Edusp, 2003. 
Peña Saavedra, Vicente. "As escolas que viñeron de alén mar (Galicia, ss. XVIIXXI). Algunhas réplicas dende terras lusas». Revista da Faculdade de Letras. História, III Série 3 (2002): 245-262.

Peña Saavedra, Vicente. "Los emigrantes transoceânicos como agentes de modernización educativa em el norte penunsular ». En La educación en España a examen (1898-1998), organizada por Julio Ruiz Berrio et al., 213-246. Zaragoza: Ministerio de Educación y Cultura, 1999.

Peña Saavedra, Vicente. «Presupuestos socioeducativos para la implantación de las escuelas de americanos y las Sociedades de Instrucción em Galicia». Historia de la educación 2 (1983): 359-369.

Peña Saavedra, Vicente. Êxodo, organización comunitária e intervención escolar: La impronta educativa de la emigración transoceânica. Santiago de Compostela: Xunta de Galicia, 1991.

Porta, Elaine Veiga. «Os imigrantes Espanhóis em Santos (1880-1920)». PhD diss., Universidade de São Paulo, 2008.

Sarmiento Silva, Érica. O outro rio. A emigração galega a Rio de Janeiro. Santa Comba (A Coruña): tresCtres, 2006.

Varella, Drauzio. Nas Ruas do Brás. São Paulo: Cia das Letras, 2000.

Vidal, Diana Gonçalves. «Galícia e Brasil: tecendo histórias da educação (18711936)». Sarmiento - Anuario Galego de Historia da Educación 12 (2008): 111-126.

Vidal, Diana G. y Biccas, Maurilane. «As múltiplas estratégias de escolarização do social em São Paulo (1770-1970). Cultura e prática escolares». En Educação e Reforma: o Rio de Janeiro nos anos 1920-1930, organizado por Diana Vidal, 19-44. Belo Horizonte: Argvmentvm, 2008. 